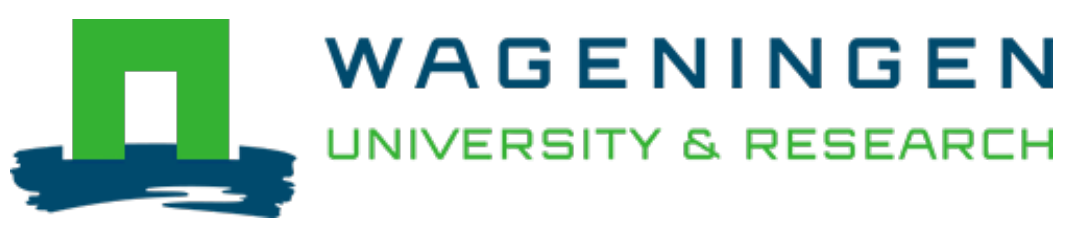

\author{
Growth of Bacillus cereus in soyabean tempeh. \\ International Journal of Food Microbiology \\ Nout, M.J.R.; Beernink, G.; Bonants-van Laarhoven, T.M.G. \\ https://doi.org/10.1016/0168-1605(87)90004-3
}

This publication is made publicly available in the institutional repository of Wageningen University and Research, under the terms of article $25 \mathrm{fa}$ of the Dutch Copyright Act, also known as the Amendment Taverne. This has been done with explicit consent by the author.

Article $25 \mathrm{fa}$ states that the author of a short scientific work funded either wholly or partially by Dutch public funds is entitled to make that work publicly available for no consideration following a reasonable period of time after the work was first published, provided that clear reference is made to the source of the first publication of the work.

This publication is distributed under The Association of Universities in the Netherlands (VSNU) 'Article $25 \mathrm{fa}$ implementation' project. In this project research outputs of researchers employed by Dutch Universities that comply with the legal requirements of Article $25 \mathrm{fa}$ of the Dutch Copyright Act are distributed online and free of cost or other barriers in institutional repositories. Research outputs are distributed six months after their first online publication in the original published version and with proper attribution to the source of the original publication.

You are permitted to download and use the publication for personal purposes. All rights remain with the author(s) and / or copyright owner(s) of this work. Any use of the publication or parts of it other than authorised under article $25 \mathrm{fa}$ of the Dutch Copyright act is prohibited. Wageningen University \& Research and the author(s) of this publication shall not be held responsible or liable for any damages resulting from your (re)use of this publication.

For questions regarding the public availability of this publication please contact openscience.library@wur.nl 


\title{
Growth of Bacillus cereus in soyabean tempeh
}

\author{
M.J.R. Nout, G. Beernink, and T.M.G. Bonants-van Laarhoven, \\ Agricultural University, Wageningen, The Netherlands \\ (Received 24 November, 1986; accepted 10 April 1987)
}

\begin{abstract}
Bacillus cereus strains isolated from retail samples of tempeh were added in levels of approx. $10^{5} \mathrm{cfu} / \mathrm{g}$ to soaking soyabeans intended for tempeh manufacture. Their growth was prevented and tempeh of good quality was obtained when the soaking resulted in acidification of the beans to $\mathrm{pH} 4.85$, but $B$. cereus could grow well (approx. $10^{8} \mathrm{cfu} / \mathrm{g}$ ) in tempeh and cause its spoilage when the soaking did not cause acidification (bean pH 5.70-6.00). Acidification of soyabeans by addition of lactic acid prior to fungal fermentation required $\mathrm{pH} \leq \mathbf{4 . 4}$ to prevent $B$. cereus growth; at this $\mathrm{pH}$, tempeh of good quality was obtained. Acidification of soyabeans with addition of acetic acid inhibited at $\mathrm{pH} \leq 5.5$ both $B$. cereus and Rhizopus oligosporus, the mould responsible for tempeh formation; hence, no tempeh could be obtained. Mixed inocula of $R$. oligosporus and either Lactobacillus plantarum, $L$. casei ssp. alactosus or $L$. fermentum produced tempeh of excellent quality. However, mixed inocula containing lactobacilli were not able to prevent $B$. cereus growth and subsequent spoilage when added to unacidified soyabeans of $\mathrm{pH}$ 6.6. This indicates that soyabean acidification, either by biological or by chemical means, is essential to inhibit $B$. cereus growth during the tempeh fermentation.
\end{abstract}

Key words: Tempeh; Soyabean; Fermented foods; Bacillus cereus; Lactobacillus

\section{Introduction}

Tempeh is an oriental fermented food obtained by fungal solid-state fermentation of soaked and cooked soyabeans, legumes, cereals or other suitable raw materials. Its traditional manufacture and properties have been excellently reviewed by Ko and Hesseltine (1979).

Soyabean tempeh may be prepared by soaking dehulled yellow variety soyabeans overnight, followed by rinsing and cooking in tapwater for 30-90 min, draining the water and allowing the adhering water to evaporate by spreading the beans in a thin layer. After cooling to ambient temperature the beans are inoculated with a spore preparation usually of Rhizopus oligosporus, packed into sparsely perforated containers and incubated at $30-35^{\circ} \mathrm{C}$ for approx. $48 \mathrm{~h}$. The final product has a shiny white colour due to the profuse growth of non-sporulated mycelium and has a firm

Correspondence address: M.J.R. Nout, Department of Food Science, Agricultural University, De Dreijen 12, 6703 BC Wageningen, The Netherlands. 
texture due to the mycelial penetration into the tempeh mass. Prior to consumption, tempeh is subjected to a heat treatment by boiling or frying.

A recent examination of the microbiological composition of 110 retail samples of tempeh by Samson et al. (1987) revealed the general presence of lactic acid bacteria, Enterobacteriaceae and yeasts. In addition, approx. $10 \%$ of the samples contained Staphylococcus aureus and Bacillus cereus in numbers which may cause food intoxication.

In this paper we consider the effect of some processing conditions on the growth of $B$. cereus during tempeh manufacture and storage. During the stage of soaking the beans at ambient temperatures, an uncontrolled growth of microorganisms (mainly bacteria) takes place. Ko and Hesseltine (1979) report that during the traditional Indonesian process, this spontaneous fermentation results in acidification to approx. $\mathrm{pH}$ 4.5. We found this to happen as well under laboratory conditions; in addition to acidification, gas production caused foaming and the soak water became viscous. However, we observed that such fermentation may unpredictably fail to materialise; in such cases, foam and viscosity were sometimes produced but the soak water was not $(\mathrm{pH} 6.6)$ or only slightly $(\mathrm{pH}>5.5)$ acidified.

Steinkraus et al. (1965) stated that acidification during the soak was desirable in order to prevent growth of microbial contaminants during the fungal fermentation stage. They recommended that a sufficiently low $\mathrm{pH}$ of the cooked beans be ensured by soaking them in dilute acids, e.g. lactic or acetic acid, in order to counteract the effect of a failing acidification during soaking.

Tanaka et al. (1985) found that during the manufacture of tempeh from unacidified soyabeans, added contaminations of Clostridium botulinum, Staph. aureus, Salmonella typhimurium and Yersinia enterocolitica could grow very well and that clostridial and staphylococcal toxins could be produced.

\section{Materials and Methods}

Semi-traditional non-sterile process for tempeh manufacture

$1 \mathrm{~kg}$ dry abrasion-dehulled yellow variety soyabeans kept at $-20^{\circ} \mathrm{C}$ to avoid insect infestation, were rinsed twice with 111 tapwater at $45^{\circ} \mathrm{C}$, drained and soaked for spontaneous fermentation in 31 tapwater at $45^{\circ} \mathrm{C}$ in an incubator at $25^{\circ} \mathrm{C}$ for $24 \mathrm{~h}$. In most cases, such spontaneous fermentation failed to acidify resulting in soaked beans with $\mathrm{pH}$ of approx. 6 .

When fermentative acidification during the soak was required, this could be achieved by repeating the above procedure using $1 \%$ soaking water of the previous batch as a starter, as described elsewhere (Nout et al., in press).

After draining the soak water, the beans were rinsed twice with 111 tapwater at $25^{\circ} \mathrm{C}$, and boiled in 31 fresh tapwater for $20 \mathrm{~min}$. After draining and discarding the boiling water, the hot beans were immediately spread in a layer of approx. $1 \mathrm{~cm}$ thickness on a wire-mesh and turned twice to facilitate the evaporation of adhering water. 
After approx. $20 \mathrm{~min}$ the beans were hand-dry and cooled to room temperature, $20-25^{\circ} \mathrm{C}$. They were then transferred into a container and mixed with $10 \mathrm{ml}$ spore suspension. This spore suspension was obtained by adding $9 \mathrm{ml}$ sterile peptone saline $(0.85 \% \mathrm{NaCl}, 0.1 \%$ Oxoid L34 peptone, $\mathrm{pH} 7.0)$ to each of 2 malt extract agar (Oxoid CM 59), slant cultures of $R$. oligosporus NRRL 5905 (incubated at $30^{\circ} \mathrm{C}$ for 1 week) followed by scraping off the spores with an inoculation needle. The concentration of $R$. oligosporus in the inoculated beans were about $10^{6} \mathrm{cfu}$ per gram.

After inoculation, 40-50 g beans were firmly packed into a $9 \mathrm{~cm}$ diameter petri dish with 4-5 perforations of $0.5 \mathrm{~mm}$ diameter in bottom and lid and incubated at $30^{\circ} \mathrm{C}$ for $45 \mathrm{~h}$, yielding fresh tempeh. Tempeh was stored in sealed PVC bags at $4^{\circ} \mathrm{C}$ for 17 days.

\section{Aseptic process for tempeh manufacture from sterile soyabeans}

$1 \mathrm{~kg}$ of soyabeans were rinsed as mentioned above, and soaked in 31 tapwater at $4{ }^{\circ} \mathrm{C}$ to avoid microbial growth. After rinsing and boiling $20 \mathrm{~min}$ in tapwater, they were spread and cooled on wire-mesh trays as mentioned above. Such beans had a pH of 6.6. They were transferred into screw-capped glass jars and sterilised by autoclaving at $121^{\circ} \mathrm{C}$ for $25 \mathrm{~min}$. When required, the bean $\mathrm{pH}$ was adjusted by addition of predetermined amounts of concentrated lactic acid or glacial acetic acid, in order to achieve the appropriate bean $\mathrm{pH}$ after sterilisation.

After cooling to room temperature, the sterilised beans were inoculated with approx $10^{6} \mathrm{cfu} / \mathrm{g} R$. oligosporus NRRL 5905 using a spore suspension as described above, and other microorganisms as required (see below). After mixing with a sterile spoon, the inoculated beans were packed into sterile petri dishes in a sterile laminar-flow working cabinet, and incubated as mentioned above.

\section{Inoculation with $B$. cereus}

B. cereus strains designated No. 8 and No. 10, isolated from retail samples of tempeh, were grown in Brain Heart Infusion (BHI) broth (Oxoid CM 225) for $24 \mathrm{~h}$ at $30^{\circ} \mathrm{C}$. For inoculation, appropriate amounts of BHI culture were added either at the start of the soaking stage during the semi-traditional nonsterile process, or to the sterilised soyabeans during the aseptic process.

\section{Inoculation with lactobacilli}

Strains of Lactobacillus plantarum, L. casei ssp. alactosus, and L. fermentum, isolated earlier from soaked soyabeans (Nout et al., in press) were grown in de Man, Rogosa \& Sharpe broth (MRS; Gibco, Scotland, No. 152-3250) for $24 \mathrm{~h}$ at $25^{\circ} \mathrm{C}$ (L. plantarum) or $37^{\circ} \mathrm{C}$ ( L. fermentum and L. casei ssp. alactosus).

To study the influence of mixed inocula of $R$. oligosporus and lactobacilli on the growth of $B$. cereus in tempeh made from unacidified soyabeans, inoculation of sterile, unacidified soyabeans $(\mathrm{pH}$ 6.6) was carried out at two levels: (A) approx. 
equal to the $B$. cereus inoculum, using $1 \mathrm{ml}$ of the $10^{-5}$ diluted MRS lactobacilli cultures per $100 \mathrm{~g}$ soyabeans, or (B) largely in excess of the B. cereus inoculum, using $1 \mathrm{ml}$ of the undiluted MRS lactobacilli cultures per $100 \mathrm{~g}$ beans. After inoculation, the exact size of the $B$. cereus and lactobacilli inocula were determined using MEPP and Rogosa agar counting plates, respectively as described below.

\section{Tempeh acceptability}

The assessment of tempeh quality for acceptability was based upon exterior colour, texture, odour and evenness of mycelial penetration into the center of the cake (Nout et al., 1985), as judged by an expert panel.

\section{Microbiological analysis}

Sample preparation: Representative samples of $10.0 \mathrm{~g}$ taken under aseptic conditions, were homogenized for $2 \mathrm{~min}$ with $90 \mathrm{ml}$ of sterile peptone saline using a Colworth type 400 Stomacher (Seward \& Co., London). Decimal dilution series were prepared by mixing $1 \mathrm{ml}$ of a previous dilution with $9 \mathrm{ml}$ of sterile peptone saline.

Total aerobic count: Pour plate counts in Plate Count Agar (PCA, Oxoid CM 325) incubated for $72 \mathrm{~h}$ at $30^{\circ} \mathrm{C}$. At low sample dilutions, i.e. -1 to $-4,0.01 \%$ cycloheximide was added to PCA to prevent overgrowth by moulds.

Enterobacteriaceae: Pour plate counts in Violet Red Bile Glucose (VRBG, Oxoid $\mathrm{CM} 485$ ) agar, with overlay, incubated for $24 \mathrm{~h}$ at $30^{\circ} \mathrm{C}$.

Yeasts: were determined in Oxytetracyclin Glucose Yeast Extract agar pour plates (OGYE, Oxoid CM 545) to which $100 \mathrm{mg} / 1$ oxytetracyclin (Terramycin, Pfizer) and $0.1 \mathrm{~g} / 1$ diphenyl (biphenyl, BDH Chemicals) were added after sterilisation; incubation 5 days at $30^{\circ} \mathrm{C}$.

Lactic acid bacteria: Pour plate counts were carried out in Rogosa agar (LBS agar BBL No. 11327, Becton Dickinson \& Co.) with overlay; the plates were incubated 3-5 days at $30^{\circ} \mathrm{C}$.

Bacterial spores: $1: 10$ dilutions in sterile peptone saline were heated at $80^{\circ} \mathrm{C}$ for $5 \mathrm{~min}$. Surviving spores were determined, by pour plate counts (PCA, $30^{\circ} \mathrm{C}, 24-72$ h) for appropriate dilutions in sterile peptone saline.

B. cereus: Determinations were conducted as surface counts on Mannitol Egg-yolk Phenol red Polymyxin (MEPP, Cereus Selektiv agar, Merck no. 5267 to which $10 \mathrm{mg}$ polymyxin B sulphate (Pfizer) and $40 \mathrm{ml} \mathrm{50 \%} \mathrm{sterile} \mathrm{egg} \mathrm{yolk} \mathrm{emulsion} \mathrm{in} 0.85 \%$ $\mathrm{NaCl}$ were added per liter of basal medium), incubated for $24 \mathrm{~h}$ at $30^{\circ} \mathrm{C}$.

Reporting of counts: Microbial counts are presented as $\log _{10}$ per $g$ of sample. The detection limit of the pour plate method is $50 / \mathrm{g}$ ( 5 colonies on plates containing 1 $\mathrm{ml}$ of $10^{-1}$ diluted sample), corresponding with $\log N=1.7$. Similarly, the detection limit of the surface streaking method is $500 / \mathrm{g}$ ( 5 colonies on plates inoculated with $0.1 \mathrm{ml}$ of $10^{-1}$ diluted sample), corresponding with $\log N=2.7$. 


\section{Results and Discussion}

\section{Growth of B. cereus during semi-traditional non-sterile processes}

B. cereus strains 8 and 10 , isolated in our laboratory from retail samples of tempeh, were tested for their growth during a semi-traditional non-sterile process aimed at simulating conditions of industrial practice.

A non-inoculated control process $\left(A_{0}\right)$ with beans which had significantly acidified during soaking, resulted in tempeh of excellent acceptability (Table I) containing mainly lactic acid bacteria with no detectable Enterobacteriaceae, $B$. cereus, bacterial spores, or yeasts.

During a non-sterile process cross-contaminations of the cooked beans take place through handling and equipment, explaining total counts of up to $2.20 \mathrm{log} \mathrm{cfu} / \mathrm{g}$. Such contaminations can multiply rapidly during the fungal fermentation stage, resulting in counts of $8-9 \mathrm{log} \mathrm{cfu} / \mathrm{g}$ in fresh tempeh.

On the other hand, Table I shows that a non-inoculated control process $\left(B_{0}\right)$ with poorly acidified beans yielded tempeh in which a normal mould growth had occurred but which was unacceptable due to its repellent off-odour, brown discolouration and sticky texture. This product contained lactic acid bacteria as well, but in addition $8.41 \log \mathrm{cfu} / \mathrm{g} B$. cereus, either originating from the raw beans or introduced as a cross-contamination.

Similarly, Table I shows that contaminations of $B$. cereus 8 (process $\mathrm{A}_{8}$ ) and $B$. cereus 10 (process $A_{10}$ ) when introduced at the start of the soak, could not grow if acidification took place, giving tempeh of good acceptability and a microbiological composition similar to that of tempeh from the non-inoculated control process $A_{0}$.

In contrast, contaminations with $B$. cereus 8 (process $B_{8}$ ) and $B$. cereus 10 (process $B_{10}$ ) at the start of the process where no acidification took place, resulted in tempeh with high levels of lactic acid bacteria, B. cereus and Enterobacteriaceae. Whereas process $\mathrm{B}_{8}$ gave unacceptable tempeh comparable to the product of process $\mathrm{B}_{0}$, process $\mathrm{B}_{10}$ produced tempeh of acceptable sensory characteristics.

During earlier investigations (Nout et al., 1985) we found that fresh soyabean tempeh of excellent acceptability has a $\mathrm{pH}$ of 6.0-6.6. Considering the $\mathrm{pH}$ values and $B$. cereus counts of the products from processes $\mathrm{B}_{0}, \mathrm{~B}_{8}$ and $\mathrm{B}_{10}$, a combination of high $B$. cereus counts (e.g. $8.80 \mathrm{log} \mathrm{cfu} / \mathrm{g}$ ) and high $\mathrm{pH}($ e.g. pH 7.40) may be associated with the spoilage symptoms of brown, sticky, and malodourous tempeh.

\section{Growth of $B$. cereus in tempeh from sterile soyabeans using an aseptic process}

Whereas a fermentative acidification of soyabeans to $\mathrm{pH} 4.85$ proved adequate to prevent the growth of naturally occurring or inoculated $B$. cereus (Table I, processes $\mathrm{A}_{0}, \mathrm{~A}_{8}$, and $\mathrm{A}_{10}$ ), we were interested in the maximum soyabean $\mathrm{pH}$ which still produces this inhibitory effect.

In order to eliminate possible interference from naturally occurring $B$. cereus on the beans, an aseptic process was used in which the $\mathrm{pH}$ of sterile soyabeans had been adjusted either with lactic acid or with acetic acid. 
TABLE II

Effect of $\mathrm{pH}$ adjustment with lactic or acetic acid on growth of $B$. cereus and $R$. oligosporus in tempeh made from sterile soyabeans (data given in $\log \mathrm{cfu} / \mathrm{g}$ tempeh)

\begin{tabular}{|c|c|c|c|c|c|c|}
\hline \multirow[t]{2}{*}{$\mathrm{pH}$} & \multicolumn{3}{|c|}{ Lactic acid } & \multicolumn{3}{|c|}{ Acetic acid } \\
\hline & $\begin{array}{l}\text { B. cereus } \\
\text { No. } 8\end{array}$ & $\begin{array}{l}\text { B. cereus } \\
\text { No. } 10\end{array}$ & $\begin{array}{l}R \text {. oligo- } \\
\text { sporus }\end{array}$ & $\begin{array}{l}\text { B. cereus } \\
\text { No. } 8\end{array}$ & $\begin{array}{l}\text { B. cereus } \\
\text { No. } 10\end{array}$ & $\begin{array}{l}\text { R. oligo } \\
\text { sporus }\end{array}$ \\
\hline 6.00 & & & & 6.50 & 6.25 & ++ \\
\hline 5.95 & 8.75 & 8.90 & $++^{a}$ & & & \\
\hline 5.90 & 8.20 & 7.60 & ++ & 6.65 & 7.20 & ++ \\
\hline 5.80 & 8.25 & 8.70 & ++ & & & \\
\hline 5.50 & 7.70 & 8.55 & ++ & $<2.7$ & $<2.7$ & 0 \\
\hline 5.20 & 7.20 & 7.10 & ++ & & & \\
\hline 5.15 & 3.85 & 3.00 & ++ & & & \\
\hline 5.10 & 5.70 & 7.60 & ++ & & & \\
\hline 5.00 & 7.20 & 7.15 & ++ & $<2.7$ & $<2.7$ & 0 \\
\hline 4.90 & 6.65 & 7.15 & ++ & $<2.7$ & $<2.7$ & 0 \\
\hline 4.80 & 5.40 & 6.20 & ++ & & & \\
\hline 4.70 & 6.20 & 6.30 & ++ & & & \\
\hline 4.55 & $<2.7$ & 2.75 & ++ & & & \\
\hline 4.45 & 4.30 & 4.40 & ++ & & & \\
\hline 4.40 & $<2.7$ & $<2.7$ & ++ & & & \\
\hline 4.35 & $<2.7$ & $<2.7$ & ++ & & & \\
\hline 3.95 & $<2.7$ & $<2.7$ & + & & & \\
\hline
\end{tabular}

${ }^{a}++$, dense mycelial growth required for tempeh; + , inadequate (floccose) mycelial growth with undesirable sporulation; 0 , fermentation failure by complete inhibition of mycelial growth.

Table II shows that when adjusted with lactic acid, a bean $\mathrm{pH}$ of 4.40 was adequate to prevent the growth of $B$. cereus strains 8 and 10 on sterile soyabeans inoculated with $R$. oligosporus. Whereas undesirable fungal sporulation occurred on beans adjusted to $\mathrm{pH} 3.95$ with lactic acid, soyabeans of $\mathrm{pH} 4.35$ produced tempeh of excellent acceptability, i.e. the growth of $R$. oligosporus had not been affected, and undesirable colour defects due to sporulation were absent.

On the other hand, if acetic acid was used to adjust the $\mathrm{pH}$ of sterile soyabeans, $\mathrm{pH} \leqslant 5.5$ was already sufficient to prevent the growth of both strains of $B$. cereus. Unfortunately, the growth of $R$. oligosporus was prevented as well by this treatment, so the product tempeh could not be obtained. At pH $5.9 R$. oligosporus was not inhibited by acetic acid, but neither were the added strains of $B$. cereus.

These results indicate that if soyabean acidification were to be obtained by the addition of acid, acetic acid must not be used.

During the non-sterile processes $\mathrm{A}_{0}, \mathrm{~A}_{8}$, and $\mathrm{A}_{10}$ (Table I), $\mathrm{pH} 4.85$ of beans acidified by fermentation was adequate to prevent $B$. cereus growth during the following stage of fungal fermentation. Although we did not analyse the nature of the organic acids present in naturally acidified soaked beans, it is highly probable that they contain both lactic and acetic acids. Considering the effect of acetic acid observed in Table II, this offers an explanation why naturally acidified beans with 
pH 4.85 achieve a significantly better inhibitory effect on $B$. cereus than beans acidified to the same $\mathrm{pH}$ using pure lactic acid.

Growth of B. cereus during aseptic processes using sterile unacidified soyabeans and mixed inocula of $R$. oligosporus and Lactobacillus spp.

Having established the inhibitory effect of natural or artificial acidification of soyabeans on the growth of $B$. cereus, we investigated whether a mixed inoculum of $R$. oligosporus and acidifying organisms could be used to inhibit the growth of $B$. cereus in unacidified beans ( $\mathrm{pH}$ 6.6) resulting from a soak during which the acidification had failed.

Table III shows that mixed inocula of $R$. oligosporus with either $L$. plantarum, $L$. casei spp. alactosus, or L. fermentum yielded tempeh of excellent acceptability when added to sterile soyabeans of $\mathrm{pH}$ 6.6. However, even high levels of added lactobacilli were not able to prevent the outgrowth of relatively small inocula of the tested $B$. cereus strains when these were added simultaneously. Apparently, the acid production by the lactobacilli is either not sufficient or not rapid enough to avoid the multiplication of $B$. cereus in unacidified soyabeans.

\section{TABLE III}

Influence of mixed inocula of $R$. oligosporus and Lactobacillus spp. on the growth of $B$. cereus in tempeh made from sterile unacidified soyabeans ( $\mathrm{pH} 6.6$ ) using an aseptic process

\begin{tabular}{|c|c|c|c|c|}
\hline $\begin{array}{l}\text { Lactobacillus } \\
\text { spp. }\end{array}$ & $\begin{array}{l}\text { Inoculation level } \\
\text { (log cfu/g beans) }\end{array}$ & $\begin{array}{r}\text { B. cereus } \\
\qquad(10\end{array}$ & $\begin{array}{l}\text { Lactic acid bacteria } \\
\mathrm{fu} / \mathrm{g} \text { tempeh) }\end{array}$ & $\begin{array}{l}\text { Tempeh } \\
\text { acceptability }^{\text {a }}\end{array}$ \\
\hline \multicolumn{5}{|c|}{ Control (not inoculated with $B$. cereus) } \\
\hline L. plantarum & 2.20 & $<2.7$ & 9.08 & ++ \\
\hline L. casei ssp. alactosus & 1.36 & $<2.7$ & 8.48 & ++ \\
\hline L. fermentum & 1.89 & $<2.7$ & 6.26 & ++ \\
\hline \multicolumn{5}{|c|}{ Inoculated with $B$. cereus No. 8 at $1.32 \log \mathrm{cfu} / \mathrm{g}$ beans } \\
\hline L. plantarum & 2.20 & 8.83 & 8.85 & - \\
\hline L. plantarum & 7.70 & 7.81 & 9.64 & + \\
\hline L. casei ssp. alactosus & 1.36 & 8.65 & 8.08 & - \\
\hline L. casei ssp. alactosus & 6.56 & 9.00 & 9.49 & +- \\
\hline L. fermentum & 1.89 & 9.00 & 6.76 & - \\
\hline L. fermentum & 7.15 & 7.66 & 9.04 & +- \\
\hline \multicolumn{5}{|c|}{ Inoculated with $B$. cereus No. 10 at $1.54 \log \mathrm{cfu} / \mathrm{g}$ beans } \\
\hline L. plantarum & 2.20 & 9.00 & 8.71 & - \\
\hline L. plantarum & 7.70 & 7.78 & 9.62 & + \\
\hline L. casei ssp. alactosus & 1.36 & 9.00 & 7.77 & - \\
\hline L. casei ssp. alactosus & 6.56 & 8.62 & 9.36 & +- \\
\hline L. fermentum & 1.89 & 9.04 & 6.20 & - \\
\hline L. fermentum & 7.15 & 8.45 & 8.95 & +- \\
\hline
\end{tabular}

a See Table I for explanation. ++ , excellent; +, good; + - , fair; -, unacceptable. 
Inoculation of sterile unacidified soyabeans with $R$. oligosporus and approx. equal quantities of $B$. cereus and Lactobacillus spp. resulted in a malodourous, brown and sticky product.

Although the addition of an excess of lactobacilli as compared to B. cereus yielded products of fair to good appearance, consistency and odour, it can be seen from Table III that these products contained dangerously high numbers of $B$. cereus. This does not only illustrate that heavy inoculation of unacidified beans with lactobacilli cannot prevent the multiplication of a contamination with $B$. cereus. It also indicates that the processing of unacidified beans with a mixed inoculum of $R$. oligosporus and lactobacilli creates a public health risk, as the spoilage which would have otherwise occurred due to the large number of $B$. cereus is apparently masked by the lactobacilli.

\section{Conclusion}

It is concluded that acidification of soyabeans, either by fermentation or by lactic acid addition, during soaking for tempeh manufacture is an essential requirement for the prevention of $B$. cereus growth and associated risks of poisoning and spoilage. Furthermore, the presence of a majority of lactobacilli may contribute to the acceptability of tempeh and may offer a secondary inhibition to undesirable microorganisms by providing a competitive environment.

\section{References}

Ko, S.D. and C.W. Hesseltine, 1979. Tempe and related foods. In: Economic Microbiology, Vol. 4, Microbial Biomass, edited by A.H. Rose, Academic Press, London, pp. 115-140.

Nout, M.J.R., T.M.G. Bonants-van Laarhoven, R. de Dreu and I.A.G.M. Gerats, 1985. The influence of some process variables and storage conditions on the quality and shelf-life of soybean tempeh. Antonie van Leeuwenhoek 51, 532-534.

Nout, M.J.R., M.A. de Dreu, A.M. Zuurbier and T.M.G. Bonants-van Laarhoven. Ecology of controlled soyabean acidification for tempeh manufacture. Food Microbiol., in press.

Samson, R.A., J.A. van Kooij and E. de Boer, 1987. A survey of the microbiological quality of commercial tempeh in the Netherlands. J Food Protect. 50, 92-94.

Steinkraus, K.H., J.P. van Buren, L.R. Hackler, and D.B. Hand, 1965. A pilot-plant process for the production of dehydrated tempeh. Food Technol. 19, 63-68.

Tanaka, N., S.K. Kovats, J.A. Guggisberg, L.M. Meske and M.P. Doyle, 1985. Evaluation of the microbiological safety of tempeh made from unacidified soyabeans. J. Food Protect. 48, 438-441. 